\title{
Decision-Making by School Principals and Education Researchers: The Dilemma of Reverse Coding in Structural Equation Modeling and its Resolution in a Study of Risk-Taking in Decision- Making for School Principals
}

\author{
By Karen Trimmer
}

This paper explores a theoretical dilemma that arose during a study of risk-taking in decision-making for public school principals in Western Australia. Western Australia is one of six Australian States. It is geographically diverse, including extremely remote schools serving Indigenous communities. The governance mechanism for public schools in Western Australia mandates policy and procedures for decision-making by principals. Principals take risks when they make decisions that are not compliant with established policy, as they may be exposed to criticism should negative outcomes arise. This creates a dilemma for principals who need to be able to respond to locally identified school and community needs, and simultaneously comply with all State and Commonwealth departmental requirements. A theoretical model of factors impacting on reasoned risk-taking in decision-making was developed and data collected through survey of a stratified random sample of principals in 253 Western Australian public schools. The analysis used methodology that combined sequential use of psychometric and traditional measurement techniques. This paper focuses on the cause and solution of a reverse coding problem that arose in structural equation modeling. The dilemma posed by this methodological issue had not been previously considered in the literature. It is reflected in the dilemmas posed to principals who are making decisions in their schools based on universal policy that does not necessarily account for the unique circumstances of their communities, schools and locations.

\section{Introduction}

This paper refers to a study that investigated whether reasoned risk-taking in decision-making by Western Australian public school principals is a consequence of their perceptions of the governance mechanism of policies and

*Associate Professor and Assistant Dean Staffing, University of Southern Queensland, Australia. 
procedures, the experience of individual principals and the characteristics of key stakeholders within the school community (Trimmer, 2011). Public schools in Western Australia fall under the jurisdiction of the Department of Education, a state government agency responsible for the provision of education at government funded schools throughout Western Australia. The responsibility for schools includes the provision of pre-primary, primary, and secondary schooling to students across over 800 school sites. Western Australia is geographically diverse covering an area of 2,529,875 square kilometres and accounting for 33 percent of the continent of Australia. The location and characteristics of its public schools reflect this diversity, including metropolitan schools in cities, regional schools in towns, and extremely remote schools serving Indigenous communities.

Principals of public schools are provided with guidance for their decisionmaking by centrally developed policy and procedures included on the regulatory framework. The regulatory framework provides a mechanism for assuring regulatory compliance across all government funded schools. It consists of the Acts, Regulations, delegations, policies and procedures that together establish the mandatory rules of governance for all officers of the Department of Education and is used by principals in decision-making within the school environment (Department of Education and Training, 2004).

This type of governance mechanism is consistent with many organisations where policies and procedures are developed to be followed and complied with by all managers and staff in each branch, geographical location and circumstance. The compliance approach to decision-making assumes that policies and procedures can be developed that will apply universally to all schools regardless of contextual circumstances that apply locally. However, this governance approach can create a dilemma for the delivery of education programs in schools as principals may experience conflict in decision-making when decision solutions that provide the best educational outcomes for students do not comply with Departmental policy. Principals need to be able to respond to the locally identified needs within a school, and simultaneously comply with all State and Commonwealth departmental requirements. Principals may be exposed to risk in their decision-making through criticism for non-compliance with established policy when they are unable to meet conflicting requirements, or when negative outcomes arise from decision-making.

\section{Research Model}

A research model was developed following identification of key factors from review of the literature and analysis of preliminary qualitative data collected through semi-structured interviews from a sample of 71 principals who self-reported on aspects of decision-making and their use of the regulatory framework (Trimmer, 2003a). The model in Figure 1 proposes that the independent variables of perception of the governance mechanism of the regulatory framework and stakeholder characteristics impact on the dependent 
variable of reasoned risk-taking in decision-making for principals. It also proposes that the variable of principal experience moderates the impact of the governance mechanism variable.

Figure 1. Research Model

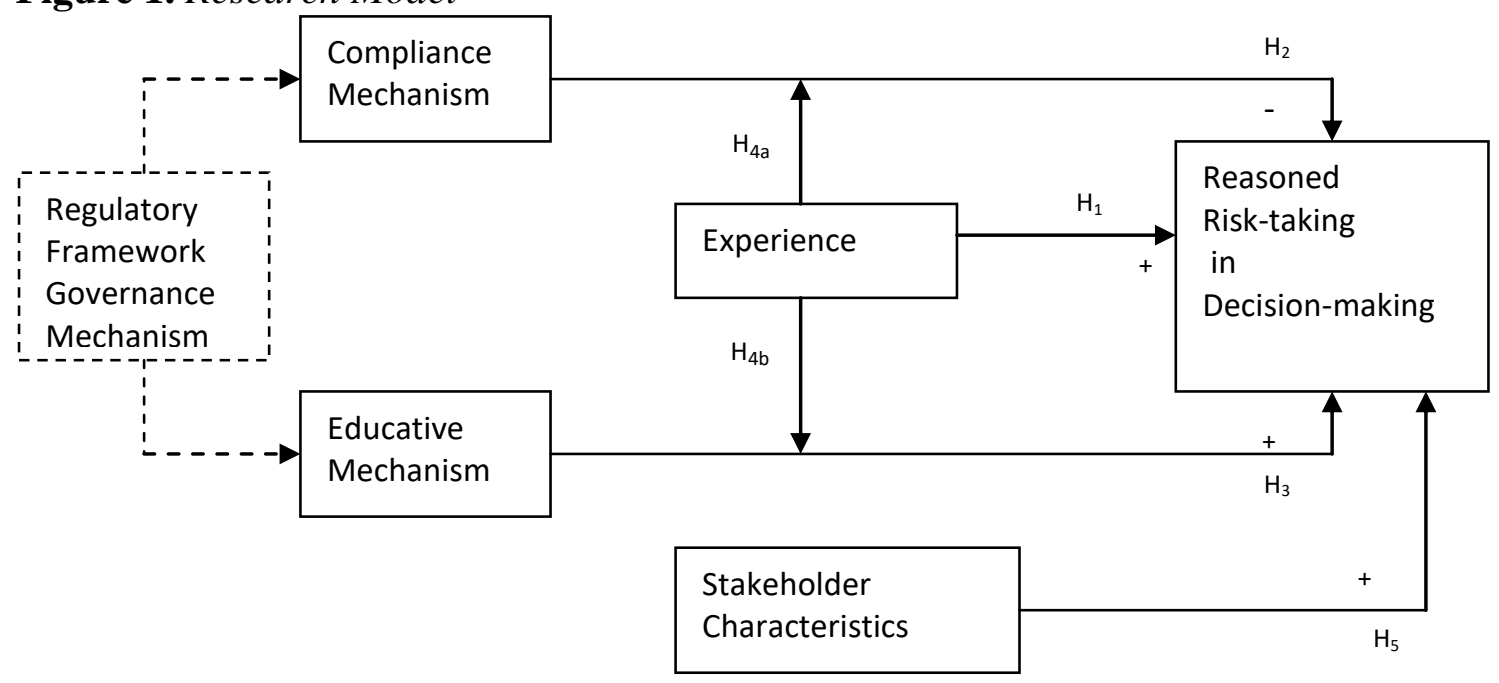

Constructs included in the research model are described below:

Regulatory Framework Governance Mechanism - The regulatory framework is the collection of policy and procedures documents disseminated to schools from the central office of the Department of Education. Compliance with these instructional statements of policy is mandatory for all staff in public schools in Western Australia. Governance structures can influence how decisions are made (Panova, 2008).

Compliance Mechanism or Educative Mechanism - A review of the regulatory framework (Trimmer, 2003a) found that it was perceived by $73 \%$ of principals as an educative tool to provide advice, instruction, guidance and clarification to assist with decision-making outcomes. In contrast to this view, other principals considered the regulatory framework to be a compliance process to control their decision-making. The focus of an organisation's governance system, on either process or outcomes, impacts on perceptions of risk and hence decision-making behaviour (Sitkin \& Pablo, 1992). In the public school context, the compliance view of the regulatory framework focuses on process, whereas an educative view focuses more on assisting a principal to achieve an appropriate outcome.

In making decisions, the likelihood of managerial risk-taking is also impacted by the decision-makers' knowledge and values (Hambrick \& Mason, 1984; Wiseman \& Gomez-Meija, 1998). Singh (1986) argues that the extent of control through level of delegation of authority is also a relevant factor. In the context of schools, principals' knowledge, their perception of the purpose and value of the governance mechanism of the regulatory framework, and their authority to make decisions, will impact on their decision-making. 
Experience - Decision-making is impacted by previous experience, with individual risk-taking more likely where managers have relevant experience as this effects expectations related to magnitude and probability of loss associated with taking a particular risk (Carpenter, Pollock \& Leary, 2003; Wiseman, Gomez-Mejia \& Fugate, 2000). The greater a manager's experience and past success with dealing with an action, the less uncertainty that manager will have regarding the likely outcome of taking the action, and the more reasonable the risk will seem. Differences in perceptions regarding the usefulness of policy and procedures in decision-making were found between groups of principals (Trimmer, 2003a) with experienced principals expressing preference for provision of minimal mandatory policy that specified outcomes to be achieved and greater flexibility to make decisions at the school level to meet outcomes. These principals indicated that their professional expertise provided a sound basis for meeting these outcomes in a manner that was better suited to the local community. Conversely new or acting principals, who had limited experience, were more likely to express a preference for clearly documented policy and prescribed procedures to provide guidance and assist them in the decisionmaking process.

Stakeholder Characteristics - The critical role of stakeholders in reasoned risk-taking and strategic decision-making has been examined in business contexts (Carpenter, Pollock \& Leary, 2003; Carpenter \& Westphal, 2001). In the context of decision-making by school principals the stakeholders include parents and community members in the school locality. Where a school is located in a community that differs from the norm, the expectations and needs of the community are more likely to be unique to that particular community. Differences could be due to factors including geographical location or cultural influence such as would occur in remotely located communities. The expectations and needs of such communities are less likely to align well to policies that have been developed centrally to apply to generally applicable circumstances. Principals' responses (Trimmer, 2003a \& 2003b) emphasised the diversity that exists between geographical locations and types of schools, with principals needing flexibility to make decisions that take account of local school and community circumstances, including geographical and cultural factors.

Reasoned Risk-taking in Decision-making - Risk-taking occurs when decisions are made that are not compliant with the governance mechanism. When negative outcomes arise from decision-making, principals may be exposed to criticism or disciplinary action for non-compliance with established policy.

Whilst, policy and procedures included within the regulatory framework are mandatory, the 2003 review found that only six percent of principals always complied with policy (Trimmer, 2003a, p.30). Seventy percent of principals indicated awareness of instances where compliance had not been possible given the circumstances (Trimmer, 2003a, p.32). These principals indicated that they used professional discretion to make decisions that took account of local circumstances, including geographical and cultural factors. 
Principals indicated that they worked around constraints as best they were able. However, they expressed concern that they were put into a vulnerable position by policies where they could not comply.

\section{Method}

A survey questionnaire was developed to measure the constructs in the research model. Measurement scales in existing studies related to business environments were not transferable to an educational context. Measurement items were therefore developed for each identified construct based on the literature and the findings from the preliminary qualitative research.

Demographic items were included at the beginning of the questionnaire. Gender, education level, experience in education and age were demographic variables included in studies measuring attitude and behavioural dimensions in school reform (Dunham, Grube, Gardener, Cummings \& Pierce, 1989; Hogue $\&$ Lord, 2007). Other demographic items included the experience and expertise of the principal in regard to length and type of teaching and administrative experience and the type and size of school. Geographical location and ethnic composition of the school had also been previously included as environmental and situational factors likely to influence the construct of "Stakeholder Influences" (Dunham et al., 1989).

The survey was sent to principals in a sample of 253 schools across the state of Western Australia. A stratified random sample of schools was selected on the basis of district, geographical location, school type, and school size. The sample was selected to be representative across these strata at a $95 \%$ confidence level. The data analysis involved four procedures. Firstly, a preliminary statistical analysis of the items in the questionnaire using SPSS (2003). Following this, a Rasch analysis was conducted to explore the psychometric properties of the measurement instrument (Andrich, Sheridan \& Luo, 2005). Having established that the questionnaire provided a valid and reliable scale of measurement, an analysis of the model incorporating these constructs was conducted using factor analysis. Finally, the hypotheses were tested using Partial Least Squares structural equation modeling (Chin, 2001).

Structural equation modeling (SEM) includes an assessment of the measurement model as a component of the analysis. However, the presence of errors of measurement and their influence on the fit of the data to the model are only revealed after the fit statistics have been estimated. Cavanagh and Romanoski (Waugh, 2005) recommend the use of Rasch probabilistic analysis during scale construction to identify measurement errors due to person and item misfit. This allows the errors to be minimised by discarding misfitting items prior to undertaking factor analysis and SEM. 


\section{Factor Analysis}

The aim of the factor analysis was to determine whether items in the questionnaire were loading onto the constructs they were developed to measure and subsequently to remove highly correlated items by replacing them with a smaller number of uncorrelated items for each construct. Data reduction can simplify subsequent multivariate techniques by identifying the most parsimonious set of variables to include in the analysis that adequately represent the original set of variables (Hair, Black, Babin, Anderson \& Tatham, 2006).

The principal components method of extraction was used to find linear combinations of items accounting for as much variation across responses as possible. Component factor analysis is most appropriate for data reduction as it considers the total variance represented in the original set of variables to derive the minimum number of factors needed for prediction purposes (Hair et al., 2006). Items with a large component of variance in common are useful to retain as an indicator of the construct in the final SEM analysis. In determining how many factors to retain, the potential reduction of data was weighed against the loss of complexity of the original data set. The items relating to each of the components in the solution were also scrutinised with reference to the literature and outcomes of the preliminary interviews with principals. Hair et al. (2006, p.110) advises that "the researcher should always consider the conceptual underpinnings of the variables and use judgment as to the appropriateness of the variables". In this study, the selection of factors was aligned to the theoretical basis on which the questionnaire was developed. Components with eigenvalues greater than 1 that were supported by the theoretical literature were retained as indicators for each construct. A summary of the factors and an interpretation of their meaning from the literature are shown in Table 1. Retained components are shaded.

Table 1. Retained Components for Each Model Construct

Construct 1 Compliance Governance Mechanism

Total variance explained $52.3 \%$

\begin{tabular}{|c|c|}
\hline Component 1 & Delegation of authority; perceived control; pressure to align \\
\hline Component 2 & Obligation to comply and be accountable \\
\hline Component 3 & System control of process; lack of perceived control \\
\hline Component 4 & Perceptions of leaders' preferences \\
\hline \multirow{2}{*}{\multicolumn{2}{|c|}{$\begin{array}{l}\text { Construct } 2 \text { Educative Governance Mechanism } \\
\text { Total variance explained } 70.9 \%\end{array}$}} \\
\hline & \\
\hline Component 1 & Focus on outcomes \\
\hline Component 2 & Provides assistance \\
\hline \multicolumn{2}{|c|}{ Construct $3 \quad$ Experience } \\
\hline \multicolumn{2}{|c|}{ Total variance explained $65.2 \%$} \\
\hline Component 1 & Substantive appointment and length of time \\
\hline Component 2 & Relevance of experience \\
\hline Component 3 & Past success \\
\hline Component 4 & Past negative experience; risk aversion \\
\hline
\end{tabular}




\begin{tabular}{|c|c|}
\hline Component 5 & Type of experience \\
\hline Component 6 & Past success achieving outcomes \\
\hline \multirow{2}{*}{\multicolumn{2}{|c|}{$\begin{array}{l}\text { Construct } 4 \quad \text { Stakeholder Characteristics } \\
\text { Total variance explained } 64.4 \%\end{array}$}} \\
\hline & \\
\hline Component 1 & Geography; cultural composition \\
\hline Component 2 & Seek community input as incomplete understanding \\
\hline Component 3 & Diversity \\
\hline Component 4 & Stakeholder input \\
\hline Component 5 & District \\
\hline \multicolumn{2}{|c|}{$\begin{array}{l}\text { Construct } 5 \\
\text { Total variance explained } 69.8 \%\end{array}$} \\
\hline Component 1 & Take responsibility to meet outcomes; flexible \\
\hline Component 2 & Necessary to meet needs \\
\hline Component 3 & Pressured and compliant \\
\hline Component 4 & Focus on process; little incentive to take risks \\
\hline Component 5 & Reference after decision made \\
\hline
\end{tabular}

As a result of both the Rasch and factor analyses the most representative items with sound measurement properties were retained. The Rasch analysis was undertaken to ensure that the items formed a reliable measurement scale of principals' attitudes and behaviours. Eleven items were found to have disordered thresholds and discarded from further analysis as misfitting the model. Following the factor analysis a further 15 items were deleted to provide a parsimonious group of items that loaded highly and were representative of the underlying constructs.

\section{Structural Equation Modeling}

Partial Least Squares (PLS) is a second generation SEM technique that allows analysis of all paths simultaneously for each of the dependent variables included in the research model (Barclay, Thompson \& Higgins, 1995; Chin, 1998; Gefen, Straub \& Boudreau, 2000). The constructs in the proposed model are modeled as variables in PLS. Compliance governance mechanism and educative governance mechanism are reflective variables in that they are made up from indicator variables that are manifestations of the same underlying construct. In contrast, the variable experience is constructed from a range of unrelated indicator variables that measure more than one aspect of experience. The indicator variables associated with time or length of experience as a principal, measure a different aspect of experience than those associated with nature or type of experience. These aspects of experience may be considered to be composite elements of the construct experience. Variables such as this that account for multiple aspects of a meso-level construct are considered to be formative variables (Gefen, Straub \& Boudreau, 2000; Chin, 1998). Similarly, stakeholder characteristics is a formative variable in that it is based on multiple unrelated aspects of stakeholders including education district and geographical location, size of school, and diversity of cultural composition. The PLS technique supports the analysis of models containing formative 
variables whereas covariance based SEM are interpreted to support only reflective observed variables (Gefen, Straub \& Boudreau, 2000; Barclay, Thompson \& Higgins, 1995; Chin, 2001) and is therefore an appropriate choice for the model developed in this study.

PLS was run initially to analyse the model with the items identified as misfitting or unreliable by Rasch analysis or the factor analysis deleted and the reliability of each item assessed by examining the loadings of each measure. The loading is a measure of the correlation of each item with its respective construct. The results in Table 2 show that four items $(15,47,49$ and 50) did not meet the reliability criterion and were therefore dropped from the next iteration of the analysis in order to improve the reliability of retained items.

Table 2. PLS Factor Loadings of Items for Compliance Mechanism

\begin{tabular}{|cc|c|c|}
\hline $\begin{array}{c}\text { Compliance } \\
\text { Mechanism }\end{array}$ & $\begin{array}{c}\text { Iteration 1 } \\
\text { Loading }\end{array}$ & $\begin{array}{c}\text { Compliance } \\
\text { Mechanism }\end{array}$ & $\begin{array}{c}\text { Iteration 2 } \\
\text { Loading }\end{array}$ \\
\hline Q14 & -0.63 & Q14 & 0.65 \\
\hline Q15 & -0.23 & & \\
\hline Q17 & -0.44 & Q17 & 0.46 \\
\hline Q18 & -0.56 & Q18 & 0.56 \\
\hline Q20 & 0.52 & Q20 & -0.51 \\
\hline Q22 & -0.77 & Q22 & 0.78 \\
\hline Q47 & 0.00 & & \\
\hline Q49 & -0.04 & & \\
\hline Q50 & 0.28 & & \\
\hline
\end{tabular}

\section{The Dilemma of Reverse Coding}

Following removal of the reflective indicators that did not meet the established loading criterion, a revised model was re-run in PLS. The numerical values of the loadings were either unaltered or changed marginally and met the criterion for each item. However, the direction of the loadings for all items measuring construct 1, Compliance Governance Mechanism, had reversed. In the first iteration, this construct had a negative impact on the dependent variable as predicted by the theory. Following removal of low loading items this effect was reversed to a positive impact, whilst the direction of influence of all other constructs remained unchanged. The results of the second iteration are shown in Table 2 for the reflective indicators. The reversed items are highlighted.

In order to investigate this dilemma, a revised model was re-run using a higher threshold value for internal consistency and three additional items removed. The reliability of each reflective variable in the revised model was either unaltered or changed marginally. However, the direction of the loadings for all items measuring construct 1, Compliance Governance Mechanism, was again reversed as in the previous iteration of the model. Given that this unanticipated result was not due to the level of the loading criterion further investigation was undertaken. 
The model was subsequently re-run iteratively removing each of the items $15,47,49$ and 50 one at a time. Regardless of order of removal, it was found that the reversal of the direction of the relationship for construct 1 occurred when all four items were removed. The literature was silent on the causes and resolution of the problem of reverse coding. Advice was sought from the creators of PLS, Smart PLS and other users regarding this difficulty. Professor Bido (personal email communication, 6 March, 2008) advised that the construct may be comprised of more than one factor. This can be determined by running a principal component analysis with only the items for the construct to see how they were grouped. Previously Bido (personal communication, 28 February, 2008) had indicated that although it is usual practice to drop items with lower loadings for reflective latent variables it is possible, if too many items are dropped, to be left with items that reflect another latent variable than that hypothesised. It was possible that this could be the cause of the reverse coding in this case.

As a principal component analysis had been conducted as part of the methodology, the results were re-examined in light of the advice on the reverse coding dilemma. On review of the factor analysis, it was noted that the construct Compliance Governance Mechanism was made up of four factors:

- Delegation of authority; perceived control; pressure to align;

- Obligation to comply and be accountable;

- System control of process; lack of perceived control; and

- Perceptions of leaders' preferences.

Each of these factors was supported by the literature (Libby \& Fishburn, 1977; Vlek \& Stallen, 1980; Hambrick \& Mason, 1984; Singh, 1986; Deci \& Ryan, 1987; Sitkin \& Pablo, 1992; Wiseman \& Gomez-Mejia, 1998; Reeve, Nix \& Hamm; 2003; Trimmer, 2003a \& 2003b; Whiteley A, 2004; Wirtz, Cribb \& Barber, 2005; MacNeill \& Silcox; 2006) as being as an important component of this construct. Items 49 and 50 both provided a measure of the factor Perceptions of leaders' preferences and in removing both items from the analysis there remained no measure of this factor for the construct. On reflection, it appeared that removal of these items had resulted in the construct being altered to a different construct from that originally developed in the model. Therefore, in order to analyse the hypothesised model, it was determined that item 50 should be retained. Item 50 had the higher of the loadings of the two items measuring the factor. It is considered valid to include an item with a low loading where there is a legitimate measurement reason for doing so (Barclay, Thompson \& Higgins, 1995; Hulland, 1999; Plouffe, 2001). In this case, the rationale was to retain the integrity of the hypothesised construct.

An assessment of the measurement model was then conducted and average variance extracted (AVE) found for each latent variable (Fornell \& Larcker, 1981). The model was re-run with low loading items (17, 48 and 64) removed 
to improve AVE. Whist removal of the three items improved AVE it again had the effect of reversing the direction of the relationship between the variables Compliance Mechanism and Reasoned Risk-taking in Decision-making. The model was subsequently re-run iteratively removing individual and pairs of items. With item 48 removed the correlation changed to a positive result.

The results of the factor analysis were consulted at this point in relation to the construct Reasoned Risk-taking in Decision-making. The principal components analysis showed that this construct was made up of five factors:

- Take responsibility to meet outcomes; flexible;

- Necessary to meet needs;

- Pressured and compliant;

- Focus on process; little incentive to take risks; and

- Reference after decision made.

These factors were supported by the results of the qualitative study, feedback from the pilot questionnaire and literature (Baird \& Thomas, 1985; Deci \& Ryan, 1987; MacCrimmon \& Wehrung, 1990; Trimmer, 2003a \& 2003b; Soane \& Chmiel, 2005; Wirtz, Cribb \& Barber, 2005). Item 48 was one of three items developed to provide a measure of the factor Pressured and Compliant. One of these items had been removed, leaving only two items as measures of this factor. Removal of item 48 appeared to be a further example of reverse coding where removal of the item resulted in the measured construct being altered to a different construct from that originally developed in the model. Therefore, it was determined that item 48 should be retained on the rationale of retaining the integrity of the hypothesised construct, consistent with the argument for retention of item 50 (Barclay, Thompson \& Higgins, 1995; Hulland, 1999; Plouffe, 2001).

\section{Conclusion}

The reverse coding dilemma challenged the usual practice of removing items with low loadings for reflective latent variables when they reflect aspects of the construct that have been established as important components from the literature. Where too many items are dropped items it may lead to reversal of correlations that reflect a different latent variable to that hypothesised. In such cases there is a strong argument for retention of low loading items to retain the integrity of the hypothesised construct. As this dilemma had not been previously discussed in the literature the solution required some risk-taking in decision-making by the researcher. Established literature is effectively the scholar's governance mechanism for making decisions related to the research process.

In regard to Western Australian public school principals, the results of the final analysis showed support for the hypothesised model and identified factors impacting on risk-taking in decision-making. The results indicated that the 
model explained $47.4 \%$ of the variance in reasoned risk-taking in decisionmaking. Principals' perception of the purpose of the governance mechanism of the regulatory framework impacted significantly on risk-taking in decisionmaking and that this was mediated by the level and type of experience of the principal. These findings have implications for organisations with governance frameworks based on a compliance approach where control is held within a centralised hierarchical structure. Both the level and type of experience of principals were found to have significant influence on risk-taking in decisionmaking, with implications for governance structures and the devolution of control for decision-making and accountability for outcomes in schools. In regard to stakeholder characteristics, principals' of schools with a high degree of uniqueness were significantly more likely to make decisions involving reasoned risk-taking. This finding has implications for decision-makers in contexts involving Indigenous populations or those with large proportions of migrants or refugees where there are differences in cultures and community needs and where English is a second language. Geographical location is also a consideration and the remote nature of communities where schooling and other public services are delivered is likely to impact on decision-making in those communities.

\section{References}

Andrich, D., Sheridan, B., \& Luo, G. (2005). Rasch Unidimensional Measurement Model (RUMM2020) Perth: RUMM Laboratory.

Baird, I. S., \& Thomas, H. (1985). Toward a contingency model of strategic risk taking. Academy of Management Review, 10(2), 230-243.

Barclay, D., Thompson, R., \& Higgins, C. A. (1995). The Partial Least Squares (PLS) Approach to Causal Modeling, Personal Computer Adoption and Use as an Illustration. Technology Studies: Special Issue on Research Methodology, 2(2), 285-324.

Bido, D. (2008, 28 February \& 6 March). [personal email communication].

Carpenter, M. A., Pollock, T. G., \& Leary, M. M. (2003). Testing a Model of Reasoned Risk-Taking: Governance, the Experience of Principals and Agents, and Global Strategy in High-Technology IPO Firms. Strategic Management Journal, 24, 803-820.

Carpenter, M. A., \& Westphal, J. D. (2001). The strategic context of external network ties: Examining the impact of director appointments on board involvement in strategic decision making. Academy of Management Journal, 44(4), 639-660.

Cavanagh, R. F., \& Romanoski, J. T. (2005). Sequential Application of Rasch Analysis and Structural Equation Modeling to Investigate Elementary School Classroom Learning Culture. In R. F. Waugh (Ed.), Frontiers in Educational Psychology: Nova Science Publishers, Inc.

Chin, W. W. (2001). PLS Graph User's Guide 3.0.

Deci, E., \& Ryan, R. (1987). The support of autonomy and the control of behaviour. Journal of Personality and Social Psychology, 53(6), 1024-1037.

Dunham, R. B., Grube, J. A., Gardener, D. G., Cummings, L. L., \& Pierce, J. L. (1989). The Inventory of Change in Organisational Culture. Madison: Naranda. 
Department of Education and Training. (2004). Regulatory Framework CD.

Fornell, C., \& Larcker, D. (1981). Evaluating structural equation models with unobservable variables and measurement error. Journal of Marketing Research, $18,39-50$.

Gefen, D., Straub, D. W., \& Boudreau, M.-C. (2000). Structural equation modeling and regression: Guidelines for research practice. Communications of the Association for Information Systems, 4(7).

Hair, J. F. J., Black, W. C., Babin, B. J., Anderson, R. E., \& Tatham, R. L. (2006). Multivariate Data Analysis (6th ed.). New Jersey: Pearson Education International.

Hambrick, D. C., \& Mason, P. A. (1984). Upper echelons: The organization as a reflection of its top managers. Academy of Management Review, 9, 193-206.

Hogue, M., \& Lord, R. G. (2007). A multi-level, complexity theory approach to understanding gender bias in leadership. The Leadership Quarterly, 18, 370-390.

Hulland, J. (1999). Use of partial least squares (PLS) in strategic management research: A Review of Four Recent Studies. Strategic Management Journal, 20(2), 195-204.

Libby, R., \& Fishburn, P. C. (1977). Behavioural models of risk taking in business decisions: A survey and evaluation. Journal of Accounting Research, 15, 272292.

MacCrimmon, K. R., \& Wehrung, D. A. (1990). Characteristics of risk taking executives. Management Science, 36(4), 422-435.

Panova, A. (2008). Governance structures and decision making in Russian higher education institutions. Russian Social Science Review, 49(5), 76-93.

Plouffe, C. R., Hulland, J. S., \& Vandenbosch, M. (2001). Research Report: Richness versus parsimony in modeling technology adoption decisions-understanding merchant adoption of a smart card-based payment system. Information Systems Research, 12(2), 208-222.

Reeve, J., Nix, G., \& Hamm, D. (2003). Testing models of the experience of selfdetermination in intrinsic motivation and the conumdrum of choice. Journal of Educational Psychology, 95(2), 375-392.

Singh, J. (1986). Performance, slack, and risk taking in organizational decision making. The Academy of Management Journal, 29(3), 562-585.

Sitkin, S. B., \& Pablo, A. L. (1992). Reconceptualizing the determinants of risk behaviour. Academy of Management Review, 17(1), 9-38.

Soane, E., \& Chmiel, N. (2005). Are risk preferences consistent? The influence of decision domain and personality. Personality and Individual Differences, 38, 1781-1791.

SPSS Version 12. (2003): Apache Software Foundation.

Trimmer, K. (2003a). Review of the Regulatory Framework: Education Department of Western Australia.

Trimmer, K. (2003b). Review of the West Australian Department of Education Regulatory Framework. Paper presented at the Australian Association for Research in Education, Auckland, New Zealand.

Trimmer, K. (2011). Non-compliance by school principals: the effects of experience, stakeholder characteristics and governance mechanisms on reasoned risk-taking in decision-making. DBA, Curtin University of Technology, Perth.

Vlek, C., \& Stallen, P.-J. (1980). Rational and personal aspects of risk. Acta Psychologica, 45, 273-300.

Whiteley, A. (2004). Enlightenment the age of reason Curtin Graduate School of Business. Perth. 
Wirtz, V., Cribb, A., \& Barber, N. (2005). Reimbursement decisions in health policyextending our understanding of the elements of decision-making. Health Policy, 73, 330-338.

Wiseman, R. M., \& Gomez-Meija, L. R. (1998). A behavioral agency model of managerial risk taking. Academy of Management Review, 23(1), 133-153.

Wiseman, R. M., Gomez-Meija, L. R., \& Fugate, M. (2000). Rethinking compensation risk. In S. L. Rynes \& B. Gerhart (Eds.), Compensation in Organizations. San Francisco: Josey-Bass. 
